ENCYCLOPEEDIE Encyclopédie berbère

BERBERE

32 | 2010

32 | Mgild - Mzab

\title{
Mil (Préhistoire)
}

\section{Roubet}

\section{OpenEdition}

Journals

Édition électronique

URL : https://journals.openedition.org/encyclopedieberbere/604

DOI : 10.4000/encyclopedieberbere.604

ISSN : 2262-7197

\section{Éditeur}

Peeters Publishers

\section{Édition imprimée}

Date de publication : 31 décembre 2010

Pagination : 5021-5022

ISBN : 978-90-429-2369-0

ISSN : 1015-7344

\section{Référence électronique}

C. Roubet, « Mil (Préhistoire) », Encyclopédie berbère [En ligne], 32 | 2010, document M116a, mis en ligne le 06 novembre 2020, consulté le 17 février 2022. URL : http://journals.openedition.org/ encyclopedieberbere/604; DOI : https://doi.org/10.4000/encyclopedieberbere.604

Ce document a été généré automatiquement le 17 février 2022.

(c) Tous droits réservés 


\section{Mil (Préhistoire)}

\section{Roubet}

1 En Algérie, c'est avec Amekni que le Pennisetum entre dans le domaine alimentaire des populations Négroïdes du Néolithique saharo-soudanais, vers $8670 \pm 150 \mathrm{BP}$, soit 8225-7492 cal BC (Camps 1968).

2 La détermination de deux grains de pollens découverts à 1,40m de profondeur, fut établie sans ambiguïté, à partir de sédiments non contaminés, ni perturbés. Cette découverte et cette identification résultent de minutieux travaux de palynologie conduits par P. Guinet et D. Planque (1968, p.186-188). Dans la famille des Composées « la séparation entre Tubuliflores et Liguliflores a été faite : les Liguliflores dominent dans le niveau 1,40 m. La mise en évidence dans ce niveau de céréales (pennisetum) nous fait interpréter l'abondance de liguliflores (du type Launaea-Picris) comme pouvant indiquer un défrichement sur sol sableux ». L'analyse générale de 802 grains de pollens identifiés dans ce niveau souligne la rareté et l'exceptionnelle conservation de ces deux documents «ayant $64 \mu$ diamètre, taille ne correspondant à aucune graminée saharienne...il s'agit d'un Pennisetum cultivé » (Guinet et Planque 1968, p. 188).

3 Cette information reste à ce jour unique; les présomptions en faveur d'une mise culture de cette graminée restent très vraisemblables, mais elles se transformèrent en «quasi-certitude» pour G. Camps, qui relia ce fait incontestable aux nombreuses cuvettes de broyage*, aménagées dans les croupes granitiques du site d'Amekni, ainsi qu'aux meules, molettes et autres récipients hémisphériques, à large ouverture, que contenaient tous les dépôts (Camps 1974, p. 226).

4 Les recherches conduites en Libye dans l'Acacus saharien ont récemment livré de rares témoins botaniques de Sorghum et Pennisetum à Uan Tabu (Mercury 2001), à Ti-n-Torha Two caves et à Uan Muhuggiag* (Wasylikowa 1993), non encore reconnus comme formellement domestiques, mais qui ne contredisent pas du tout les autres résultats d'Amkeni.

5 De nos jours, le rôle majeur que joue le mil dans l'alimentation (à l'état cru ou cuit en bouillies ou galettes, etc.) d'un très grand nombre d'individus en Afrique et dans l'Ahaggar* en particulier (Gast et Adrian 1965) devrait inciter les chercheurs à 
poursuivre en Algérie l'enquête sur les origines et la diffusion de cette ressource naturelle, autochtone.

\section{BIBLIOGRAPHIE}

CAMPS G., 1968 - Amekni, Néolithique ancien du Hoggar, Mémoire X du CRAPE, Paris, AMG.

CAMPS G., 1974 - Les civilisations préhistoriques de l'Afrique du Nord et du Sahara, Paris, Doin.

GAST M., 1965 - Mils et sorgho en Ahaggar. Etude ethnologique et nutritionnelle, Mémoire IV du CRAPE, Paris, AMG.

GUINET P. et PLANQUE D., 1968 - «Résultats de l'analyse pollinique », in G. Camps, Amekni, op.cit., p. $186-188$

MERCURY A.-M., 2001 - "Preliminary analyses of fruits and seeds from the Early Holocene Sequence", In GARCEA E.A.A., (ed.) Uan Tabu in the settlement history of the Libyan Sahara, Firenze, All'Insegna del Gigli, p. 189-210.

WASYLIKOWA K., 1993 - "Plant macrofossils from the archaeological sites of Uan Muhuggiag and Tin-Torha. Southwestern Libya" In Krzyzaniak L. Kobusiewicz M. and Alexander J. (eds.), Environmental change and human culture in the Nile Basin and Northern Africa until the second millennium B.C. Poznan, Archaeological Museum, p. 25-47.

INDEX

Mots-clés : Agriculture, Alimentation, Botanique, Préhistoire, Sahara, Sahel 